\title{
MENANAMKAN KONSEP CATUR PARAMITA PADA ANAK USIA DINI DI LINGKUNGAN KELUARGA DAN SEKOLAH
}

\author{
Oleh \\ I Komang Wisnu Budi Wijaya \\ Institut Hindu Dharma Negeri Denpasar \\ wisnu.budiwijaya240191@gmail.com \\ $\boldsymbol{A}$ \\ BSTRACT
}

Gold generation 2045 candidates need to be equipped with character of education in order to grow into a fully Indonesian human being. One of the character values that can be implanted is Catur Paramita. Character values in the Catur Paramita are universal so it is worth instilled in early age children and it has a match with the value of the nation's character and core competencies of early age children education in the Kurikulum 2013. In addition, early age children is experiencing a cognitive and character on their golden age so it is the right momentum to instill the Catur Paramita character education. Instilling the concept of Catur Paramita in early age children requires certain strategies and the role of parents and teachers.

Keywords : Catur Paramita, Early childhood, Family Education

\begin{abstract}
ABSTRAK
Calon generasi emas 2045 perlu dibekali dengan pendidikan karakter agar tumbuh menjadi manusia Indonesia seutuhnya. Salah satu nilai karakter yang bisa ditanamkan adalah Catur Paramita. Nilai karakter pada Catur Paramita bersifat universal sehingga layak ditanamkan pada anak sejak usia dini serta memiliki kecocokan dengan nilai karakter bangsa serta kompetensi inti pendidikan anak usia dini pada Kurikulum 2013. Selain itu, anak usia dini sedang mengalami masa keemasan secara kognitif dan karakter sehingga menjadi momentum yang tepat untuk menanamkan pendidikan karakter Catur Paramita. Penanaman konsep Catur Paramita pada anak usia dini memerlukan strategi tertentu dan peran orang tua dan guru.
\end{abstract}

Kata Kunci : Catur Paramita, Anak Usia Dini, Pendidikan Keluarga

\section{PENDAHULUAN}

Pada periode tahun 2010-2045, Indonesia mendapat bonus demografi berupa jumlah penduduk usia produktif lebih banyak daripada usia nonproduktif. Menurut data BPS tahun 2011, pada tahun itu terdapat kurang lebih 45,93 juta anak usia 0-9 tahun. Ketika sudah memasuki tahun 2045, mereka akan berusia antara 35-45 tahun (Patoerroman, 2012). Mereka nantinya diharapkan oleh pemerintah Indonesia akan tumbuh menjadi generasi emas yang nantinya akan membangun Indonesia menjadi lebih baik. Indikator dari generasi emas 2045 itu antara lain adalah bermartabat, cerdas, berdaya saing global dan berkarakter. Oleh karena itu, mereka perlu dibekali dengan berbagai hal agar bisa tumbuh menjadi generasi emas 2045 sesuai dengan indikator yang ditetapkan 
Salah satu hal yang ditanamkan kepada calon generasi emas 2045 adalah pendidikan karakter. Pendidikan karakter sebaiknya sudah ditanamkan ketika mereka masih berusia dini (0-5) tahun. Hal ini disebabkan pada usia tersebut mereka sedang mencapai usia keemasan (golden age). Di masa tersebut, perkembangan anak sedang mencapai tahap optimal. Menurut kajian neurologi dan psikologi, ketika baru lahir bayi memiliki kurang lebih 100 milyar sel neuron dan menghasilkan trilyunan sambungan antar neuron. Selain itu, perkembangan otak anak mencapai $50 \%$ ketika usia 4 tahun (Uce, 2017). Dengan demikian, pada usia ini merupakan momentum yang tepat untuk mengembangkan kognitif dan karakter anak usia dini.

Ajaran agama Hindu banyak mengandung nilai-nilai etika yang mengatur bagaimana manusia bersikap untuk diri sendiri dan orang lain. Salah satu konsep etika Hindu adalah Catur Paramita. Catur Paramita terdiri dari Maitri (persahabatan), Karuna (cinta kasih), Mudita (simpati) dan Upeksa (toleransi). Ajaran ini nampaknya cocok ditanamkan kepada anak usia dini untuk membentuk karakter generasi emas 2045. Ada beberapa hal yang mendasari bahwa nilai etika pada Catur Paramita cocok ditanamkan pada anak usia dini. Pertama, nilai etika Catur Paramita bersifat universal sehingga cocok diamalkan oleh semua umat. Kedua, seorang generasi emas harus memiliki modal individu (human capital) dan modal sosial (social capital). Konsep Catur Paramita ini bisa dijadikan modal bagi anak usia dini untuk bersosialisasi dengan individu lainnya. Ketiga, era globalisasi merangsang tumbuhnya jiwa individualisme dan cenderung menurunkan rasa persahabatan, cinta kasih dan toleransi. Hal ini yang sebenarnya memicu terjadinya berbagai konflik masyarakat yang belakangan ini semakin marak sehingga penting bagi anak usia dini ditanamkan etika Catur Paramitha agar nantinya di masa mendatang mereka bisa tumbuh menjadi generasi yang menyukai nuansa kekeluargaan, persahabatan dan penuh rasa toleransi.
Dalam menanamkan konsep Catur Paramita pada anak, memerlukan strategi dan peran orang tua dan guru. Orang tua merupakan pendidik utama dan pertama bagi anak usia dini. Sedangkan guru merupakan pendidik anak secara formal sekaligus membantu anak untuk memantapkan segala ilmu dan karakter yang telah ditanamkan oleh orang tuanya.

\section{B. Isi \\ B.1 Catur Paramita}

Catur Paramita berasal dari dua kata yaitu Catur yang berarti empat dan Paramita yang berarti luhur (Suhardana, 2006). Jadi, Catur Paramita bermakna sebagai empat perbuatan luhur yang semestinya dilakukan oleh umat Hindu agar tercipta keharmonisan dengan Tuhan Yang Maha Esa, sesama manusia dan dengan lingkungan. Catur Paramita terdiri dari empat bagian yaitu :

a. Maitri

Kata Maitri berasal dari kata Mitra yang artinya teman (Susanti, 2017). Jadi, Maitri merupakan suatu perbuatan luhur manusia untuk senantiasa mencari teman atau sahabat dan membuat kedamaian, keharmonisan dan kenyamanan dalam persahabatan tersebut. Manusia pada hakekatnya merupakan makhluk sosial yaitu makhluk yang tidak bisa memenuhi kebutuhan dan mencapai tujuannya tanpa bantuan orang lain. Oleh karena itu, manusia hendaknya harus bisa hidup rukun, damai dan menghindarkan kebencian serta permusuhan.

\section{b. Karuna}

Karuna berarti cinta kasih (Suhardana, 2006). Manusia yang berkarakter luhur hendaknya memiliki jiwa cinta kasih. Jiwa cinta kasih tidak hanya ditujukan kepada saudara, keluarga atau kekasihnya saja namun untuk semua makhluk ciptaan Tuhan. Jiwa cinta kasih dapat dilakukan dengan cara menolong orang yang sedang mengalami kesusahan dan rela berkorban demi orang lain. Jika semua manusia bisa menerapkan konsep Karuna maka niscaya akan tercipta keharmonisan di muka bumi ini. 
c. Mudhita

Mudhita adalah salah satu bagian dari Catur Paramita yang berarti simpati. Jadi, Mudhita adalah sikap manusia yang senantiasa bersimpati dengan orang lain. Sikap simpati ini dapat ditunjukkan dengan turut merasakan kesedihan atau penderitaan orang lain dan turut bahagia atas kebahagiaan yang dicapai orang lain. Dengan demikian, manusia akan terhindar dari rasa dendam, iri hati dan dengki. Ketenangan lahir dan batin akan tercapai jika sifat Mudhita tertanam di hati sanubari setiap manusia.

\section{d. Upeksa}

Upeksa berarti toleran. Sikap Upeksa penting dimiliki oleh setiap manusia. Pada dasarnya, Tuhan menciptakan manusia dengan kelebihan dan kekurangan yang bervariasi. Oleh karena itu, sudah sewajarnya manusia memaklumi atau mentoleransi kekurangan orang lain dan mengapresiasi kelebihan orang lain. Seorang yang Upeksa biasanya tidak suka menghina kekurangan orang lain, meremehkan kemampuan orang lain serta tidak suka mencampuri urusan pribadi orang lain (Susanti, 2017).

\section{B.2 Kesesuaian konsep Catur Paramita dengan Nilai Pendidikan Karakter dan Kompetensi Inti Anak Usia Dini} Kementerian Pendidikan dan Kebudayaan merumuskan delapan belas nilai karakter bangsa yang harus ditanamkan kepada peserta didik untuk pelaksanaan pendidikan karakter. Nilai tersebut yaitu :

1. Religius

2. Jujur

3. Toleransi

4. Disiplin

5. Kerja keras

6. Kreatif

7. Mandiri

8. Demokratis

9. Rasa ingin tahu

10. Semangat Kebangsaan

11. Cinta tanah air

12. Menghargai prestasi
13. Bersahabat

14. Cinta damai

15. Gemar membaca

16. Peduli lingkungan

17. Peduli sosial

18. Tanggung jawab

Jika dikaitkan dengan konsep Catur Paramita maka sebagian dari nilai pendidikan karakter berkaitan dengan konsep tersebut. Keterkaitan tersebut disajikan dalam Tabel 1 sebagai berikut.

Tabel 1. Keterkaitan Konsep Catur Paramita dengan Nilai Pendidikan Karakter

\begin{tabular}{|l|l|l|}
\hline No & $\begin{array}{l}\text { Konsep Catur } \\
\text { Paramita }\end{array}$ & $\begin{array}{l}\text { Nilai Pendidikan } \\
\text { Karakter Terkait }\end{array}$ \\
\hline 1 & Maitri & $\begin{array}{l}\text { Jujur, bersahabat, } \\
\text { peduli sosial } \\
\text { dan semangat } \\
\text { kebangsaan, cinta } \\
\text { damai }\end{array}$ \\
\hline 2 & Karuna & $\begin{array}{l}\text { Peduli sosial, } \\
\text { peduli lingkungan } \\
\text { dan cinta tanah air } \\
\text { dan religius }\end{array}$ \\
\hline 3 & Mudhita & $\begin{array}{l}\text { Menghargai } \\
\text { prestasi dan } \\
\text { tanggung jawab }\end{array}$ \\
\hline 4 & Upeksa & $\begin{array}{l}\text { Toleransi dan } \\
\text { demokratis }\end{array}$ \\
\hline
\end{tabular}

Dalam Kurikulum 2013, terdapat kompetensi inti sebanyak empat tipe yaitu kompetensi inti spiritual (KI-1), kompetensi inti sosial (KI-2), kompetensi inti pengetahuan (KI-3) dan kompetensi inti keterampilan (KI-4). Masing-masing kompetensi inti tersebut diuraikan lagi ke dalam kompetensi dasar (KD). Jika dikaitkan dengan konsep Catur Paramita sangat berkaitan dengan kompetensi-kompetensi dasar dan kompetensi inti. Kaitannya dapat dilihat pada Tabel 2. 
Tabel 2. Keterkaitan Konsep Catur Paramita dengan Kompetensi Inti dan Kompetensi Dasar di PAUD

\begin{tabular}{|c|c|c|c|}
\hline No & \begin{tabular}{|c} 
Konsep Catur \\
Paramita
\end{tabular} & Kompetensi Inti & Kompetensi Dasar \\
\hline \multirow[t]{3}{*}{1} & \multirow[t]{3}{*}{ Maitri } & $\begin{array}{l}\text { Memiliki perilaku hidup sehat, rasa ingin } \\
\text { tahu, kreatif dan estetis, percaya diri, } \\
\text { disiplin, mandiri, peduli, mampu bekerja } \\
\text { sama, mampu menyesuaikan diri, jujur, dan } \\
\text { santun dalam berinteraksi dengan keluarga, } \\
\text { guru dan/atau pengasuh, dan teman (KI-2) }\end{array}$ & $\begin{array}{l}\text { 1. } \begin{array}{l}\text { Memiliki perilaku yang dapat } \\
\text { menyesuaikan diri }\end{array} \\
\text { 2. } \begin{array}{l}\text { Memiliki perilaku yang } \\
\text { mencerminkan sikap jujur }\end{array} \\
\text { 3. } \begin{array}{l}\text { Memiliki perilaku yang } \\
\text { mencerminkan sikap rendah hati } \\
\text { dan santun kepada orang tua, } \\
\text { pendidik, dan teman }\end{array}\end{array}$ \\
\hline & & $\begin{array}{l}\text { Mengenali diri, keluarga, teman, } \\
\text { pendidik dan/atau pengasuh, lingkungan } \\
\text { sekitar, teknologi, seni, dan budaya di } \\
\text { rumah,tempat bermain dan satuan PAUD } \\
\text { dengan cara: mengamati dengan indra } \\
\text { (melihat, mendengar, menghidu, merasa, } \\
\text { meraba); menanya; mengumpulkan } \\
\text { informasi; mengolah informasi/ } \\
\text { mengasosiasikan, dan mengomunikasikan } \\
\text { melalui kegiatan bermain (KI-3) }\end{array}$ & $\begin{array}{l}\text { 1. Mengenal lingkungan sosial } \\
\text { (keluarga, teman, tempat } \\
\text { tinggal, tempat ibadah, budaya, } \\
\text { transportasi) } \\
\text { 2. Mengenal emosi diri dan orang } \\
\text { lain }\end{array}$ \\
\hline & & $\begin{array}{l}\text { Menunjukkan yang diketahui, dirasakan, } \\
\text { dibutuhkan, dan dipikirkan melalui bahasa, } \\
\text { musik, gerakan, dan karya secara produktif } \\
\text { dan kreatif, serta mencerminkan perilaku } \\
\text { anak berakhlak mulia (KI-4) }\end{array}$ & $\begin{array}{l}\text { Menunjukkan reaksi emosi diri secara } \\
\text { wajar }\end{array}$ \\
\hline \multirow[t]{2}{*}{2} & Karuna & $\begin{array}{l}\text { Memiliki perilaku hidup sehat, rasa ingin } \\
\text { tahu, kreatif dan estetis, percaya diri, } \\
\text { disiplin, mandiri, peduli, mampu bekerja } \\
\text { sama, mampu menyesuaikan diri, jujur, dan } \\
\text { santun dalam berinteraksi dengan keluarga, } \\
\text { guru dan/atau pengasuh, dan teman (KI-2) }\end{array}$ & $\begin{array}{l}\text { Memiliki perilaku yang mencerminkan } \\
\text { sikap peduli dan mau membantu jika } \\
\text { diminta bantuannya }\end{array}$ \\
\hline & & $\begin{array}{l}\text { Mengenali diri, keluarga, teman, } \\
\text { pendidik dan/atau pengasuh, lingkungan } \\
\text { sekitar, teknologi, seni, dan budaya di } \\
\text { rumah,tempat bermain dan satuan PAUD } \\
\text { dengan cara: mengamati dengan indra } \\
\text { (melihat, mendengar, menghidu, merasa, } \\
\text { meraba); menanya; mengumpulkan } \\
\text { informasi; mengolah informasi/ } \\
\text { mengasosiasikan, dan mengomunikasikan } \\
\text { melalui kegiatan bermain (KI-3) }\end{array}$ & $\begin{array}{l}\text { Mengenal perilaku baik sebagai } \\
\text { cerminan akhlak mulia }\end{array}$ \\
\hline 3 & Mudhita & $\begin{array}{l}\text { Memiliki perilaku hidup sehat, rasa ingin } \\
\text { tahu, kreatif dan estetis, percaya diri, } \\
\text { disiplin, mandiri, peduli, mampu bekerja } \\
\text { sama, mampu menyesuaikan diri, jujur, dan } \\
\text { santun dalam berinteraksi dengan keluarga, } \\
\text { guru dan/atau pengasuh, dan teman (KI-2) }\end{array}$ & $\begin{array}{l}\text { 1. Memiliki perilaku yang } \\
\text { mencerminkan sikap taat terhadap } \\
\text { aturan sehari-hari untuk melatih } \\
\text { kedisiplinan } \\
\text { 2. Memiliki perilaku yang } \\
\text { mencerminkan sikap sabar } \\
\text { (mau menunggu giliran, mau } \\
\text { mendengar ketika orang lain } \\
\text { berbicara) untuk melatih } \\
\text { kedisiplinan }\end{array}$ \\
\hline 4 & Upeksa & Menerima ajaran agama yang dianutnya & $\begin{array}{l}\text { Menghargai diri sendiri, orang lain, dan } \\
\text { lingkungan sekitar sebagai rasa syukur } \\
\text { kepada Tuhan }\end{array}$ \\
\hline
\end{tabular}




\section{B.3 Strategi Menanamkan Konsep Catur Paramita pada Anak Usia Dini}

1. Maitri

Konsep Maitri dapat ditanamkan dengan cara :

1. Orang tua mengenalkan putraputrinya dengan tetangga dan keluarganya yang berusia sebaya. Dengan demikian anak akan belajar berteman dan bersaudara

2. Guru di sekolah senantiasa melakukan kegiatan perkenalan antar siswa ketika anak-anak memasuki PAUD

3. Orang tua dan guru senantiasa mencegah anak agar tidak melakukan perkelahian dengan teman dan saudaranya dengan cara melerai atau menyelesaikan masalah anak dengan damai

4. Orang tua harus membatasi waktu putra-putrinya untuk bermain dengan gadget atau sejenisnya dan memberikan kesempatan seluasluasnya untuk bermain bersama teman, tetangga dan saudara yang sebaya.

5. Guru dan orang tua senantiasanya menanamkan konsep semangat kebangsaan

6. Ketika guru PAUD menerapkan belajar dan bermain secara berkelompok, usahakan setiap siswa mendapatkan kelompok yang bergantian agar melatih siswa berteman dengan berbagai anak.

2. Karuna

Menanamkan konsep Karuna dilakukan dengan cara :

1. Orang tua harus melatih putraputrinya untuk belajar membantu orang lain misalnya dengan cara mengajak bekerja bersama-sama menyelesaikan pekerjaan rumah seperti membersihkan halaman, ruangan dan kegiatan lainnya

2. Mendorong putra-putrinya untuk menyumbangkan benda-benda yang tidak terpakai kepada anakanak korban bencana alam

3. Apabila ada saudara atau tetangga sebaya yang sakit, maka orang tua senantiasa mengajak putra-putrinya untuk menjenguk mereka

4. Ketika dalam proses pembelajaran di kelas ada siswa yang kesulitan, maka sebaiknya guru menyuruh siswa yang lain untuk membantunya terlebih dahulu

\section{Mudhita}

Menanamkan konsep Mudhita dapat dilakukan dengan cara :

1. Orang tua dan guru secara bersamasama mengajarkan anaknya untuk bersabar dan taat aturan

2. Lembaga PAUD harus membuat aturan yang melarang tindakan bullying

3. Lembaga PAUD membuat program rutin berupa kunjungan ke panti asuhan dengan melibatkan siswa

4. Membudayakan mengucapkan tiga kata ajaib (terima kasih, maaf dan tolong)

5. Membudayakan ucapan selamat kepada siswa yang berulang tahun dan berprestasi dan turut prihatin atas musibah yang menimpa siswa

4. Upeksa

Konsep Upeksa dapat ditanamkan dengan cara :

1. Orang tua dan guru menanamkan suatu pemahaman bahwa setiap anak dilahirkan dengan segala kelebih dan kekurangan. Kelebihannya untuk diapresiasi dan kekurangannya untuk diterima.

2. Lembaga PAUD membuat program perayaan hari besar keagamaan sesuai dengan agama-agama yang dianut siswa sehingga mereka menyadari bahwa di lingkungannya terdapat berbagai agama yang harus dihargai dan ditoleransi perbedaannya. 
B. 4 Peran Orang Tua dan Guru dalam Penanaman Konsep Catur Paramita

Dalam menanamkan konsep Catur Paramita peran orang tua dan guru adalah sebagai berikut :

1. Sebagai pendidik. Orang tua dan guru PAUD tidak hanya melatih skills dan memberikan knowledge kepada anak. Orang tua dan guru PAUD juga harus menanamkan nilai karakter dan perilaku kepada anak usia dini (Maryatun, 2016). Karakter yang dimaksud adalah karakter Catur Paramita.

2. Sebagai panutan. Menurut Piaget, anak usia dini umumnya berada pada tahap sensori motorik dan pre operasional dimana mereka belajar dengan cara meniru apa yang terjadi di lingkunganya. Dengan demikian, orang tua dan guru PAUD harus memberikan contoh karakter Catur Paramita kepada anaknya misalnya tidak berkelahi dengan suami/ istri atau rekan sesama guru, menolong orang lain, bersimpati dengan orang lain dan bersikap toleran terhadap kelebihan dan kekurangan anak.

3. Sebagai konselor. Dalam menerapkan konsep Catur Paramita, anak pasti akan menemui masalah. Misalnya ketika belajar berteman anak akan bertemu dengan teman yang nakal dan karakter buruk lainnya. Guru dan orang tua harus memberikan konseling kepada putraputrinya tentang kiat-kiat menghadapi teman yang berperilaku buruk.

4. Sebagai motivator. Guru dan orang tua senantiasa memotivasi anaknya dalam pelaksanaan nilai Catur Paramita yang telah diajarkan. Anak usia dini sangat membutuhkan motivasi dalam proses belajar.

\section{PENUTUP}

Konsep Catur Paramita bersifat universal dan memiliki kesesuaian dengan kurikulum 2013 sehingga cocok ditanamkan pada anak usia dini sebagai calon generasi emas 2045. Penanaman konsep Catur Paramita dapat dilakukan di lingkungan keluarga dan sekolah. Dalam penanaman konsep tersebut diperlukan peran orang tua dan guru PAUD. Peran orang tua dan guru PAUD adalah sebagai pendidik, panutan, konselor dan motivator.

\section{DAFTAR PUSTAKA}

Kemendikbud. 2015. Peraturan Menteri Pendidikan dan Kebudayaan Republik Indonesia No. 146 Tahun 2014 tentang Kurikulum 2013 Pendidikan Anak Usia Dini.

Maryatun, I.B. 2016. Peran Pendidik PAUD dalam Membangun Karakter Anak. Jurnal Pendidikan Anak Vol. 5 Edisi 1 Tahun 2016

Patoerroman. 2012. Generasi Emas 2045. Diakses dari http://patoerroman. wordpress.com/2012/08/ tanggal 1 Oktober 2018

Suhardana, K.M. 2006. Pengantar Etika dan Moralitas Hindu. Surabaya : Penerbit Paramita

Susanti. 2017. Penerapan Ajaran Catur Paramita Sebagai Kearifan Lokal Bali dalam Pembentukan Karakter Mahasiswa di Lingkungan STKIP Agama Hindu Singaraja. Diakses dari https://e-journal.stahn-gdepudja.ac.id/ index.php/PS/article/view/7 tanggal 1 Oktober 2018

Uce, L. 2017. The Golden Age :Masa Efektif Merancang Kualitas Anak. Diakses dari $\quad$ http://jurnal.ar-raniry.ac.id/ index.php/bunayya/article/view/1322 tanggal 1 Oktober 2018 